\title{
The Electronic Behavior of Poly(3-octylthiophene) Electrochemically Synthesized onto Au Substrate
}

\author{
Rogério Valaski $^{a}$, Liadáurea M. Moreira ${ }^{b}$, Liliana Micaroni ${ }^{b}$, and Ivo A. Hümmelgen ${ }^{a}$ \\ ${ }^{a}$ Departamento de Física, Universidade Federal do Paraná, \\ Caixa Postal 19044, 81531-990 Curitiba PR, Brazil \\ ${ }^{b}$ Departamento de Química, Universidade Federal do Paraná, \\ Caixa Postal 19081, 81531-990 Curitiba PR, Brazil
}

Received on 21 November, 2002.

\begin{abstract}
We investigate the electronic characteristics and the absorption spectra of poly(3-octylthiophene), POT, films grown by electrochemical methods onto Au substrates. We discuss the results considering the morphological factor. POT films thickness can be controlled by current density in the electropolymerization process. The film roughness depends on the thickness, being about $12 \%$ of film thickness. The samples for electrical measurements were made in sandwich structure, Au/POT/metal (metal: Ni, Al). Analyzing current-voltage data we were able to estimate the positive charge carrier mobility $\left(5 \times 10^{-4} \mathrm{~cm}^{2} \mathrm{~V}^{-1} \mathrm{~s}^{-1}\right)$ and the potential barrier height in the metal/polymer interfaces $(0.1 \mathrm{eV}$ for $\mathrm{Au} / \mathrm{POT}$ and Ni/POT and $0.85 \mathrm{eV}$ for $\mathrm{Al} / \mathrm{POT})$.
\end{abstract}

\section{Introduction}

Conjugated polymers have been object of intense research in the last years. These organic semiconductors present good mechanical features, facility of production and offer the possibility of construction of devices with larger active areas than their inorganic counterparts. Among these polymers, polythiophene and its derivatives have received special considerations. Polythiophenes have a good chemical stability upon environmental conditions and produce stable interfaces with electrode metals commonly used in electronics, like aluminum and gold [1,2]. Another important feature of polythiophene films is a large absorption coefficient in the visible range of the electromagnetic spectrum $[3,4,5]$. These characteristics make polythiophene and its derivatives interesting materials for solar cell applications [6].

One of the major problems in polymer devices is the small charge carrier mobility. The morphology of the polymer film takes important place in this situation. In amorphous materials the transport occurs via hopping between localized states and disorder contributes to a further reduction of mobility. Many methods have been used to improve the order degree or the crystallinity in polymer films $[7,8]$. The use of polymers with large side chain segments is one of the methods employed with this intent. The increase in the side chain length improves the order and the planarity of the polymer chains [9]. So, the order is expected to be higher in poly(3-octylthiophene), POT, than in other polythiophene derivatives, like poly(3-metylthiophene) and consequently, also the charge carrier mobility.

When a potential barrier energy $\varphi$ for the charge carriers injection at the interface between the electrode and the polymer is so that $\varphi>>k T$ ( $k$ is the constant of Boltzmann and $T$ is the absolute temperature) the transport is better described by Simmons current density expression, derived for thermionic injection into low mobility materials [10].

$$
J=q N_{v} \mu F \exp \left(-\frac{\varphi}{k T}\right) \exp \left(\frac{\beta F^{1 / 2}}{k T}\right)
$$

where $q$ is the elementary charge, $N_{v}$ is the effective density of states in the semiconductor, $\mu$ is the charge mobility, $F$ is the electrical field, $\beta$ is a constant and $\varphi$ is the potential energy barrier height.

In this contribution we investigate the transport features of the POT films synthesized by electrochemical methods onto $\mathrm{Au}$. The electrosynthesis allows producing thin films in the final form for device application, allying synthesis and deposition in a single step.

\section{Experimental procedure}

POT films were electrodeposited onto $\mathrm{Au}$ in a singlecompartment cell using a Microquímica MQPG-01 potentiostate. The applied current density was $3.5 \mathrm{~mA} . \mathrm{cm}^{-2}$. The electrolyte was a 0.1 mol.L ${ }^{-1}$ solution of $\mathrm{LiBF}_{4}$ in acetonitrile containing the monomer 3-octylthiophene in 0.1 mol. $\mathrm{L}^{-1}$ concentration. The counter-electrode was a $\mathrm{Pt}$ wire.

POT films were reduced (dedoped) by polarizing it to $0.1 \mathrm{~V} / \mathrm{Ag} / \mathrm{AgCl}$ for $40 \mathrm{~s}$ in a $0.1 \mathrm{~mol} . \mathrm{L}^{-1}$ solution of $\left(\mathrm{CH}_{3}\right)_{4} \mathrm{NBF}_{4}$ in acetonitrile, using the single-compartment cell and a $\mathrm{Pt}$ wire as counter electrode.

The samples for electrical measurements were made in sandwich structure, Au/POT/Ni and Au/POT/Al. Au electrodes were deposited onto glass by thermal evaporation un- 
der vacuum. The $\mathrm{Ni}$ and $\mathrm{Al}$ electrodes were deposited onto POT film (dedoped state) by the same way.

The current-voltage, $I(V)$ characteristics for $\mathrm{Au} / \mathrm{POT} / \mathrm{metal}$ devices were obtained in dark conditions. The voltage was increased stepwise (steps of $0.03 \mathrm{~V}$ and $0.02 \mathrm{~V}$ for $\mathrm{Au} / \mathrm{POT} / \mathrm{Al}$ and $\mathrm{Au} / \mathrm{POT} / \mathrm{Ni}$ devices respectively) from zero to the maximum voltage ( $3 \mathrm{~V}$ and $2 \mathrm{~V}$ for $\mathrm{Au} / \mathrm{POT} / \mathrm{Al}$ and $\mathrm{Au} / \mathrm{POT} / \mathrm{Ni}$ devices respectively), at a rate of $0.03 \mathrm{~V} . \mathrm{s}^{-1}$ (Au/POT/Al devices) and $0.02 \mathrm{~V} . \mathrm{s}^{-1}$ (Au/POT/Ni devices). After the maximum voltage was reached, the same procedure was applied with inverse polarity.

POT film thickness and roughness were determined using a Dektak 3 surface profiler. The absorption spectrum of POT film was obtained by in situ spectroelectrochemical measurement in an 8452 A HP diode array UV-visible spectrophotometer. The absorption spectrum and the cyclic voltammogram were performed with the same cell and electrolyte described above. For these measurements, POT films, with thickness of $1200 \mathrm{~nm}$, were electrosynthesized onto indium-tin-oxide (ITO) and for the absorption spectrum the film was polarized to $0.1 \mathrm{~V} / \mathrm{Ag} / \mathrm{AgCl}$.

\section{Results}

POT film thickness was controlled through deposition time control at constant current density, considering that the thickness is a function of the charge density, as shown in Fig. 1. The film roughness increases with the thickness, being around $12 \%$ of the thickness in the full thickness range measured. This value is smaller than observed in other polythiophene derivative thin films also produced by electrosynthesis, like poly (3- hexylthiophene), PHT [11] and poly(3methylthiophene), PMT [12].

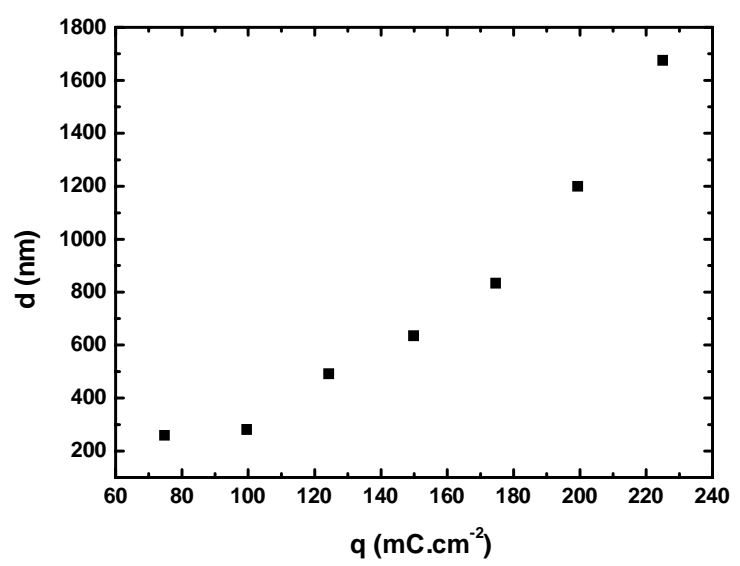

Figure 1. Film thickness $d$ of POT films deposited onto Au as a function of synthesis charge density $q$.

In Fig. 2, the absorption spectra for POT, PHT [11] and PMT [12] electrochemically deposited onto ITO are compared. It can be observed that absorption maximum is displaced to shorter wavelength in case of POT. This behavior indicates that the increase in the side chain length, for side chains longer than the 6 or 7 carbon atoms aliphatic groups, tends to induce conformational characteristics that lead to shorter effective conjugation length.

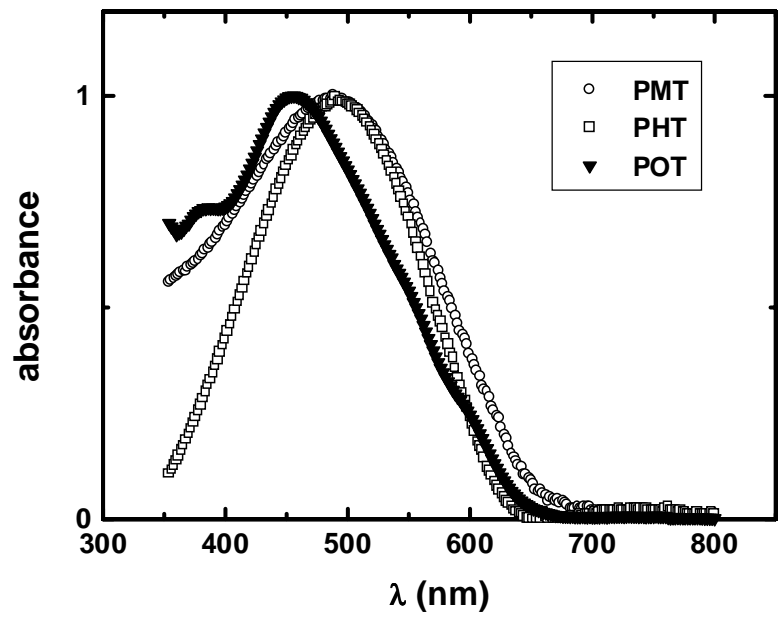

Figure 2. Absorption spectra for PMT, PHT and POT films electrochemically synthesized onto ITO in dedoped state.

In Fig. 3, the $I(V)$ plot for an Au/POT/Al with POT film thickness $(d)$ of $1200 \mathrm{~nm}$ is presented. In the inset of Fig. 3 , the same data are presented in semi-log form. From this figure the presence of a built-in potential of about $1 \mathrm{~V}$ and current rectification can be observed. This built-in potential is quite nearly the difference between the work function of the electrode materials used $\phi_{A u} \sim 5.1 \mathrm{eV} ; \phi_{A l} \sim 4.3 \mathrm{eV}$ ) [13], if polycrystalline metal $\phi$ values are assumed.

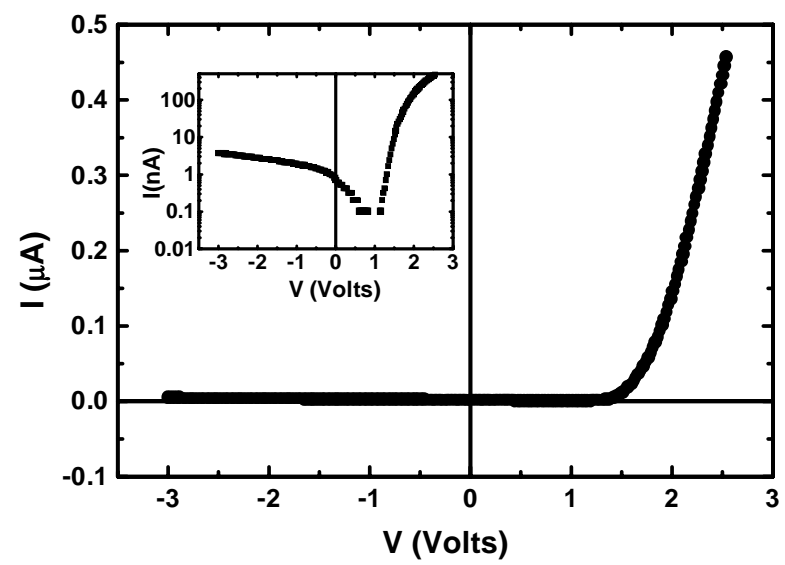

Figure 3. $I(V)$ characteristics of a Au/POT/Al; $\mathrm{V} \equiv \mathrm{V}_{A l}-\mathrm{V}_{A u}$; $d=1200 \mathrm{~nm}$. Inset: the same plot in semi-log form.

In Fig. 4, the $I(V)$ data corresponding to $\mathrm{Al}$ positively biased for an Au/POT/Al $(d=830 \mathrm{~nm})$ device are presented in the $\ln (J / V) \times V^{1 / 2}$ form. The inset of the Fig. 4 shows the relation between current density and POT thickness for $\mathrm{Au} / \mathrm{POT} / \mathrm{Al}$ devices, at constant voltage of $1.5 \mathrm{~V}$ and $\mathrm{Au}$ positively biased. The linear dependence of $\ln (\mathrm{J} / \mathrm{V})$ on $V^{1 / 2}$ (in the region indicated by straight line in Fig. 4) and the linear dependence of $\ln (J . d)$ on $d^{-1 / 2}$ (inset of Fig. 4) are indicatives of charge carrier transport limited by thermionic emission (Eq. (1)). 


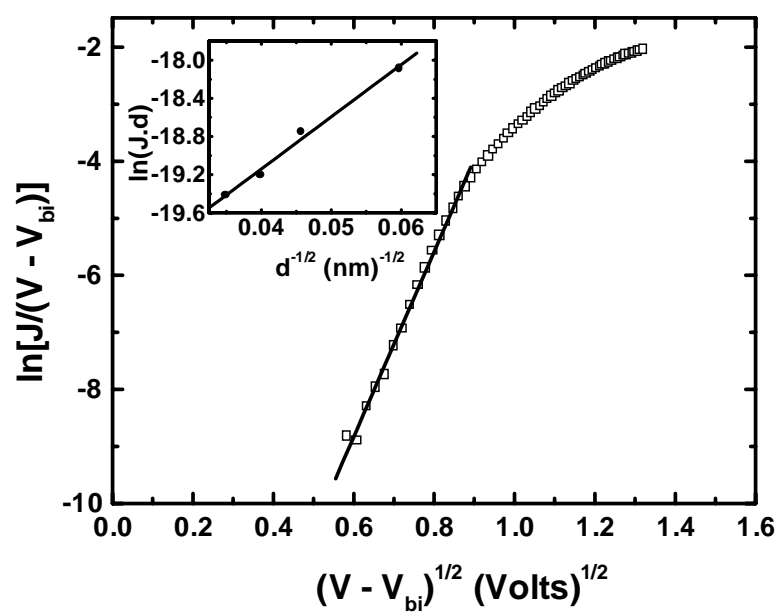

Figure 4. Electrical behavior for an Au/POT/Al devices $(\mathrm{Au}(+) ; d$ $=830 \mathrm{~nm}$ ) plotted in the $\ln (J / V) \times V^{1 / 2}$ form. Inset: dependence between density current and thickness for Au/POT/Al devices at $1.5 \mathrm{~V}$ and Au positively biased. The continuous lines represent the linear fit. $V_{b i}$ is the built-in potential.

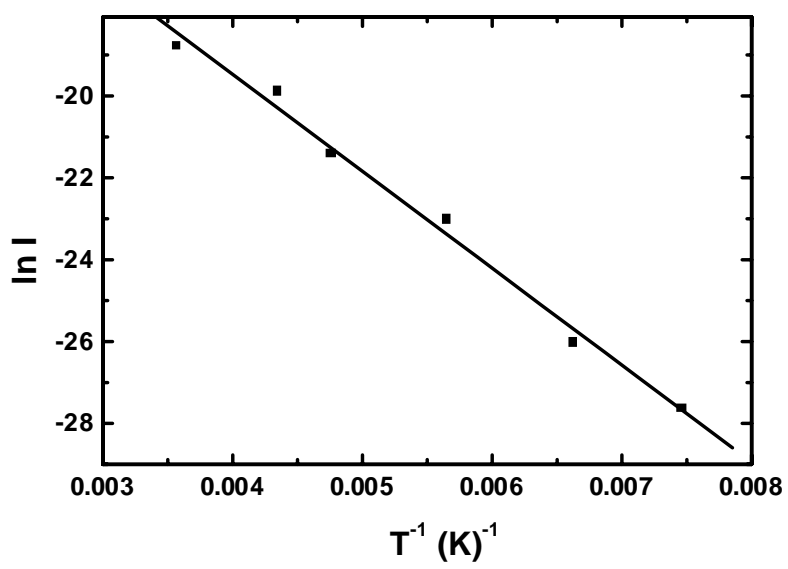

Figure 5. Temperature dependence of an Au/POT/Al device in $\ln I$ $\times T^{-1}$ form with Au positively biased. $(d=1200 \mathrm{~nm} ; 1.5 \mathrm{~V})$.

In Fig. 5 the temperature dependence of the current is shown, in the $\ln I \times T^{-1}$ form, at constant voltage of $1.5 \mathrm{~V}$ (Au positively biased and $d=1200 \mathrm{~nm}$ ). The linear behavior present in this plot is the definitive prove that in $\mathrm{Au} / \mathrm{POT} / \mathrm{Al}$ devices, with Au positively biased, the charge carrier transport is limited by thermionic injection, in agreement with Simmons model, expressed by Eq. (1).

In Fig. 6 the $I(V)$ plot for an Au/POT/Ni device $(d=$ $830 \mathrm{~nm}$ ) can be seen. It can be observed the almost symmetric behavior for both polarities (low rectification). The inset of this figure shows the $\ln (J / V) \times V^{1 / 2}$ plot for the same device when $\mathrm{Au}$ is positively biased. The linear behavior (indicated by a straight continuous line) agrees with Simmons model, Eq. (1), prediction [10]. For Ni positively biased the plot characteristics are similar. The temperature dependence of the current for an Au/POT/Ni device $(d=830 \mathrm{~nm})$, at $V$ $=1.0 \mathrm{~V}$ and Au positively biased, is shown in Fig. 7. The inset of this figure presents the thickness dependence of the current for Au positively biased at $1.0 \mathrm{~V}$. The linear behavior observed in these plots confirms that also in this case the charge carrier transport is limited by thermionic emission, as it was the case for $\mathrm{Au} / \mathrm{POT} / \mathrm{Al}$ devices, with $\mathrm{Au}$ positively biased.

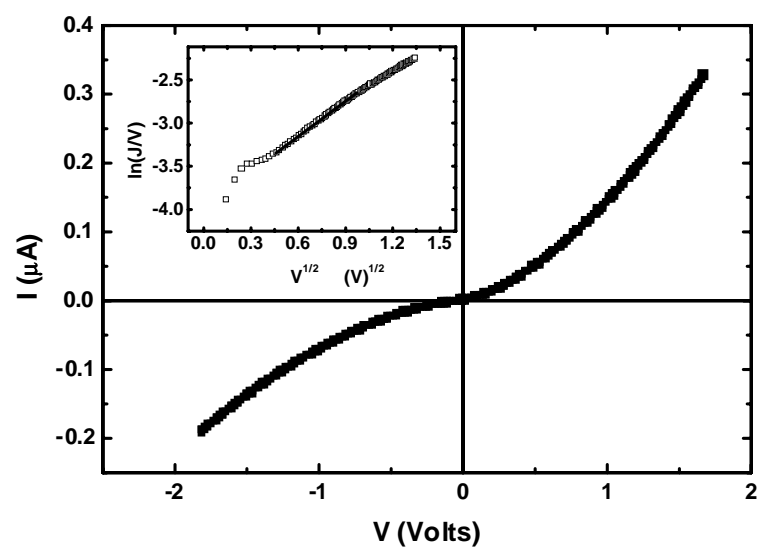

Figure 6. $I(V)$ characteristic for an Au/POT/Ni device $(d=830$ $\mathrm{nm})$. Inset: electrical behavior for the same device in $\ln (J / V / \times$ $V^{1 / 2}$ form and Au positively biased.

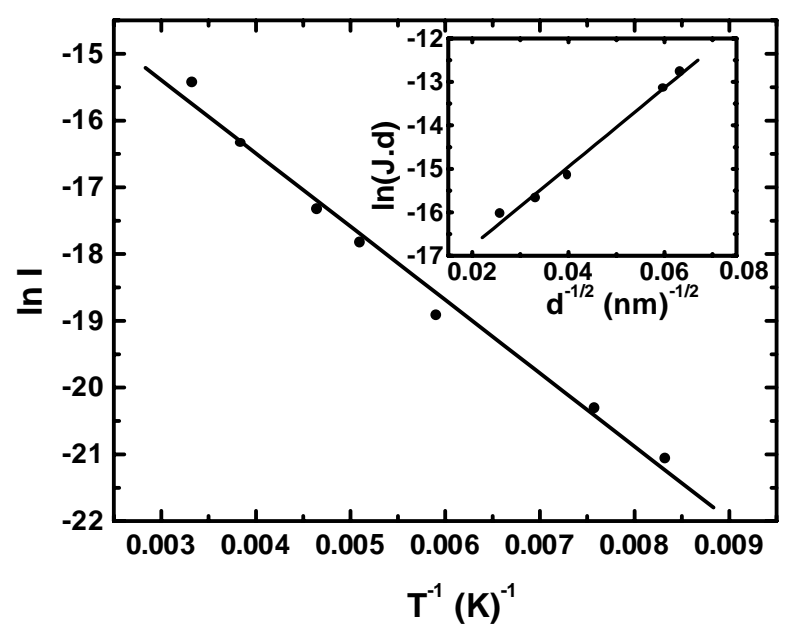

Figure 7. Dependence between current and temperature in $\ln I \times$ $T^{-1}$ form for an Au/POT/Ni device $(d=830 \mathrm{~nm} ; \mathrm{Au}(+) ; 1.0 \mathrm{~V})$. Inset: dependence between current density and thickness in $\ln (J . d)$ $\times d^{-1 / 2}$ form for this device $(d=830 \mathrm{~nm} ; \mathrm{Au}(+) ; 1.0 \mathrm{~V}$;).

We can estimate the potential energy barrier, $\varphi$, at the metal/polymer interface from $\ln I$ as a function of $T^{-1}$ data. From Eq. (1), we have $\left[\frac{\partial \ln I}{\partial T^{-1}}\right]_{V=\text { const }}=\frac{\beta d^{-1 / 2} V^{1 / 2}-\varphi}{k}$. The $\beta$ value can be calculated from the $\ln (J . d)$ as a function of $d^{-1 / 2}$ data, where we have $\left[\frac{\partial \ln J . d}{\partial d^{-1 / 2}}\right]_{V=\text { const }}=\frac{\beta V^{1 / 2}}{k T}$. For $\mathrm{Au} / \mathrm{POT}$ and Ni/POT interfaces we found $\varphi \approx 0.1 \mathrm{eV}$. In these cases $\mathrm{Au}$ and $\mathrm{Ni}$ were positively biased, so that this energy barrier is for positive charge carrier injection into the POT. For Al/POT interfaces $\varphi \approx 0.85 \mathrm{eV}$.

The linear coefficient of the linear fit region in the $\ln (I / V)$ $\times V^{1 / 2}$ can be used to estimate the positive charge carrier mobility. From Eq. (1) this coefficient corresponds to $\ln \left(\frac{q N_{v} \mu}{d}\right)-\frac{\varphi}{k T}$, where $N_{v}=2.5 \times 10^{19} \mathrm{~cm}^{-3}[14]$ is assumed. At room temperature, the mobility for positive charge carriers is then calculated: $\mu=(5.1 \pm 1.2) \times 10^{-4}$ 
$\mathrm{cm}^{2} \mathrm{~V}^{-1} \mathrm{~s}^{-1}$. In Table 1 , this mobility value is compared with those obtained by us $[11,12]$ for others polythiophene derivatives prepared by electrochemical method.

Table I: Positive charge carriers mobility for polythiophene derivatives grown by electrochemical methods: poly(3methylthiophene) (PMT) [12], poly(3-hexylthiophene) (PHT) [11] and poly (3-octylthiophene) (POT).

\begin{tabular}{|l|l|}
\hline Polymer & $\mu\left(\mathrm{cm}^{2} . \mathrm{V}^{-1} \cdot \mathrm{s}^{-1}\right)$ \\
\hline PMT & $(4.2 \pm 0.4) \times 10^{-4}$ \\
\hline PHT & $(9.4 \pm 3.0) \times 10^{-5}$ \\
\hline POT & $(5.1 \pm 1.2) \times 10^{-4}$ \\
\hline
\end{tabular}

The energy diagram estimated for POT film is presented in Fig. 9. The value of energy gap of POT, approximately $2.0 \mathrm{eV}$, was determined from absorption spectrum (Fig. 2). The HOMO (highest occupied molecular orbital) level energy was estimated from cyclic voltammogram analysis, relating the oxidation onset potential $(0.8 \mathrm{~V} / \mathrm{Ag} / \mathrm{AgCl})$ of POT (Fig. 8) with HOMO level energy and correcting it to vacuum reference level, following a procedure reported by Micaroni et al. [15]. In this way, the value obtained for the HOMO level energy of POT was $5.2 \mathrm{eV}$.

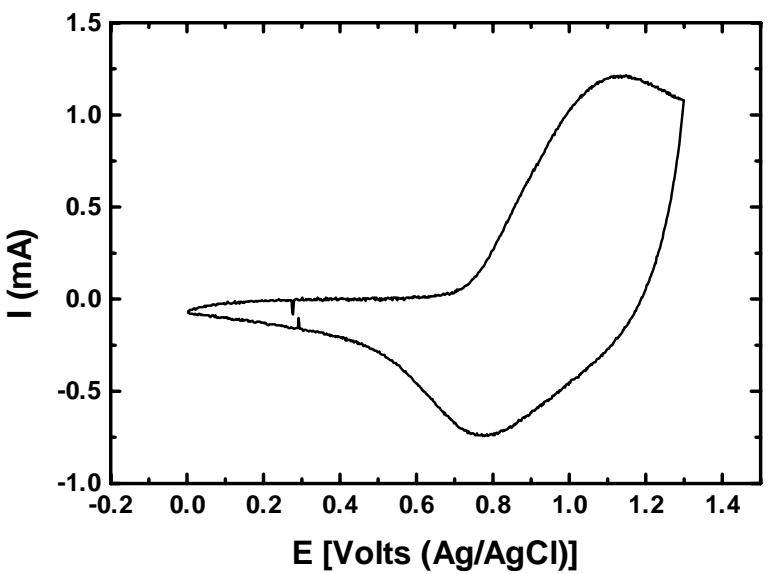

Figure 8. Cyclic voltammogram of POT film deposited onto ITO $(d=1200 \mathrm{~nm}), \mathrm{v}=30 \mathrm{mV} . \mathrm{s}^{-1}$.

\section{Discussion}

The film morphology is one of the most important features that influence charge carriers transport in a conjugated polymer. As in amorphous materials transport of charge carriers is done by hopping between sites, it is necessary to increase the order and the cristallinity to increase mobility. Another important point concerns the reduction of impurity concentration incorporated to the films. Reduced order, apart from

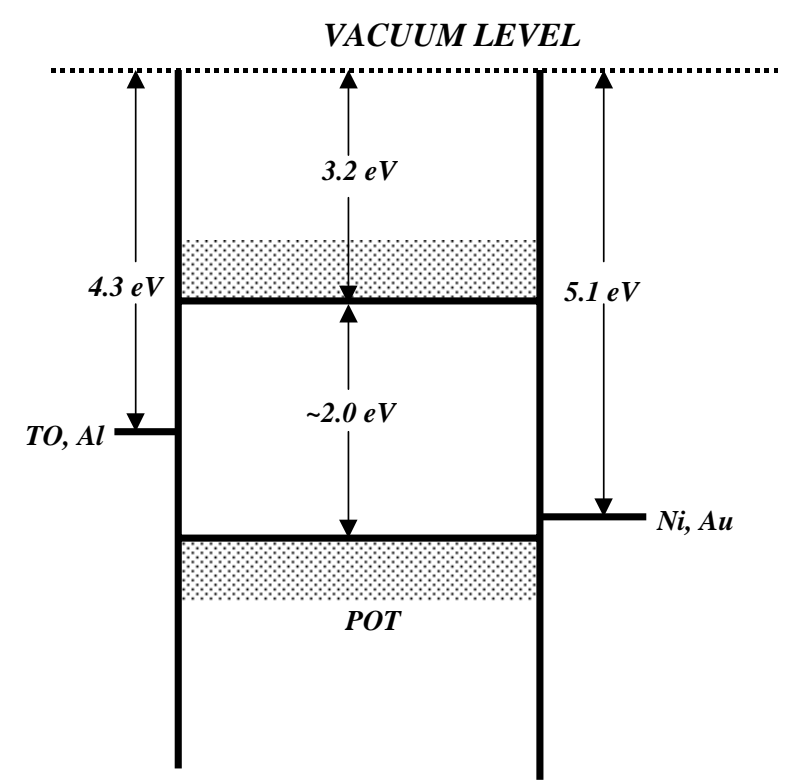

Figure 9. Energy diagram for POT compared to the work functions of the metals used in this work.

producing a larger distribution of distances between neighboring molecules also increases energetic disorder leaving to larger energy differences between neighboring sites, so that hopping of charge carriers gets more difficult. It is expected that the increase in side chain length of a polymer produces a more ordered structure and the results that have been obtained for POT films produced by chemical and by electrochemical methods agree with this trend $[16,17]$. When the side chain length is larger it seems to be more difficult to bend the main chain so that the intrachain transport is easier because there are not so many potential barriers originated by chain torsion. The mobility values present in the Table 1, however, do not demonstrate a tendency of mobility increase with increased side chain length.

Although the gap value, $2.0 \mathrm{eV}$, determined for POT in this work from the absorption onset (Fig. 2) is coherent with data reported in literature $[18,19]$, the wavelenght of the absorption maximum in the POT spectrum shown in Fig. 2 is smaller than the value reported by other groups $[18,20]$. The change in the absorbance peak value in polymer films is an indicative of the change in the morphology of these films. Sentein et al [21] have demonstrated that when the chain ordering increases the maximum of absorption displaces to higher wavelengths regions. The absorption maximum displacement to lower wavelengths (higher energies) essentially indicates that the major contribution to the absorption comes from polymer segments with shorter effective conjugation length. This situation is expected in disordered films, where conjugation is often broken due to configurational deviations from ideal non-twisted and nonbent backbone of the conjugated molecule. This existence of a large amount of polymer segments with short conjugation length allows us to understand the data of Table 1. The same configurational defects that break conjugation also hinder charge transport, limiting charge carrier mobility. 
N. Camaioni et al[20] have demonstrated the influence of the side chain length in the absorption spectra for some polythiophene derivatives. They observed that when the side chain length increases the absorption spectra maxima displace to higher wavelength regions, contrarily to our results. However, V. N. Prigodin et al [22] have shown that in polymer films the charge transport mechanism is better explained by hopping between cristalline domains surrounded by an amorphous media. The same has also been pointed out by T. Hassenkam et al[23]. The displacement of the absorption maxima to smaller wavelength in Fig. 2, suggests a larger contribution to absorption from the amorphous region around the cristalline domains. In this region, disorder is caused by the large distribution of the torsion angle between adjacent thiophene rings and the different planar positions of these rings. As large this torsion angle distribution as smaller is the charge carrier mobility [24,25,26]. Considering the exposed above and our observations concerning mobility and absorption spectra, we tentatively explain the apparent discrepancy as originated from the particular morphology due to the electrochemical deposition conditions. It suggests that our samples present a larger amount of small crystalline domains, so that even when amorphous materials presence is larger, distance between crystalline domains is lower, permitting easier hopping between them. This supposition deserves further investigation.

The positive charge carrier mobility determined in this work does not differ from the other polythiophene derivatives by more than one order of magnitude [11,12,26,27]. The mobility value is the same as found by Y. Kunugi et al [28] in chemically synthesized regioregular poly(3octylthiophene) films with $1 \%$ doping level. These authors found mobilities one order of magnitude larger for regioregular poly(3-octylthiophene) films with $0.014 \%$ doping level. Rigorously, we have determined $\mu N_{\nu}$ and calculated $\mu$ under the assumption of constant $N_{\nu}$. The adopted value of $N_{\nu}$ was used for different polymers leading to consistent results $[11,12]$, but it is expected that polymers with different side chain groups present different density of states due to differences in effective conjugation length and different conjugated to aliphatic volume occupation fraction. In spite of this limitation, it is important to stress that a larger $\mu N_{\nu}$ implies in larger injection current, which is the relevant characteristic for device applications.

The built-in potential value is defined as the difference between the work function values of the electrodes. When chemical reactions between the polymer and the electrodes occur or degradation of the polymer takes place, the builtin potential value is smaller than the difference between the work function of the electrodes [29,30]. In Au/POT/Al devices the built-in potential value nearly equals the difference between the work functions of the electrodes, suggesting that there is not significant presence of interface states at the metal/polymer interface. The stability of the Al/POT interfaces has also been noticed by Esselink et al [31]. The absence of interface states between Au and POT is in perfect agreement with the results of Sarathy et al[32] that did not observe any interaction among Au particles and POT films.

The rectification behavior of the Au/POT/Al is coherent with results observed for similar devices. Fang et al [33] and Garten et al[34] have found the rectification behavior in ITO/POT/Al and ITO/POT/Au devices. I. Musa et al [35] also have reported rectification behavior in regioregular poly(3-octylthiophene) based devices. In their contribution metal/P3OT/silicon devices (metal: Au, Al) were used. They found rectification ratios up to $10^{6}$. The values of the potential barrier heights in the present contribution also agree with values encountered by Fang et al [33]. The potential barrier height determined for the different interfaces investigated in this work are in agreement with the energy diagram shown in Fig. 9.

The curve presented in Fig. 4 requires further comments: the curve tends to a saturation value. This saturation region at higher voltages has been shown by Ma et al [36] in poly(4,4- biphenylenevinylene) and this behavior was analytically described by Koehler et al [37]. R. Valaski et al [38] also have observed these saturation regions in PPy devices when the PPy film thickness increases. The saturation is due to the transition from thermionic injection limited charge carrier transport to the space-charge limited case.

\section{Conclusions}

We have prepared poly(3-octylthiophene) thin films using electrochemical synthesis, which present mobility of positive charge carriers at room temperature of $5 \times 10^{-4}$ $\mathrm{cm}^{2} \cdot \mathrm{V}^{-1} \cdot \mathrm{s}^{-1}$. Absorption spectra indicate the existence of a large amount of chain segments with short effective conjugation length. The values obtained for the potential barriers at the polymer/electrode material interfaces suggest the quasi absence of interface states, so that the built-in potential nearly equals the difference of electrode material work functions.

\section{Acknowledgements}

The authors would like to thank PADCT/CNPq (Project 62.0081/97-0 CEMAT) for financial support. I.A.H acknowledges $\mathrm{CNPq}$ for a research fellowship. R.V. and L.M.M. acknowledge CAPES and PIBIC/CNPq, respectively, for scholarships.

\section{References}

[1] R. Hozze, "Spectroelectrochemistry of Conducting Polymers" in: Handbook of Advanced Electronic and Photonic Materials and Devices (H. S. Nalva, Ed., Academic Press, 2001).

[2] H. Y. Seung, J. E. Whitten, Synth. Met. 114, 305 (2000).

[3] A. Bock, A. Topeters, C. Kryschi, Synth. Met. 75, 133 (1995).

[4] M. Onoda, K. Tada, A. A. Zakhidov, K. Yoshin, Thin Solid Films 331, 76 (1998). 
[5] L. Micaroni, D. Dini, F. Decker, M.-A. De Paoli, J. Solid State Electrochem.3, 352 (1999).

[6] C. J. Brabec, N. S. Sariciftci, "Conjugated Polymer Based Plastic Solar Cells", in: Semiconducting Polymers Chemistry, Physics and Enginnering (G. Hadziivannou, P. F. con Hutten, Eds., Willey - VCH, 1999).

[7] R. Österbacka, G. Juska, K. Arlauskas, A. J. Pal, K. M. Kälman, H. Stubb: J. Appl. Phys. 84, 6, 3359 (1998).

[8] E. Ando, S. Onodura, M. Sino, O. Ito, Carbon 39, 101, (2001).

[9] G. Casalbore-Miceli, N. Camaioni, M. C. Gallazzi, L. Albertin, A. M. Fichera, A. Geri, E. M. Girotto, Synth. Met. 125, 307 (2002).

[10] J. G. Simmons, Phys. Rev. Lett. 15, 967 (1965).

[11] R. Valaski, L. M. Moreira, L. Micaroni, I. A. Hümmelgen, J. Appl. Phys. 92, 2035 (2002).

[12] R. Valaski, A. F. Bozza, L. Micaroni, I. A. Hümmelgen, J. Solid State Electrochem. 4, 390 (2000).

[13] D. R. Lide: CRC Handobook of Chemistry and Physics (CRC Press, 1995)

[14] P. W. M. Blom, M. J. M. de Jong, C. T. H. F. Liedenbaum, Polym. Adv. Technol. 9, 390 (1998).

[15] L. Micaroni, F. C. Nart, I. A. Hümmelgen, J. Solid State Electrochem. 7, 55 (2002).

[16] Z. Gao, L. Zhou, H. Huang, Thin Solid Film 347, 146 (1999).

[17] K. E. Aasmundtveit, E. J. Samuelsen, J. Mardalen, E. Bakken, P. H. J. Carlsen, U. Lienert, Synth. Met. 89, 203 (1997).

[18] T. Ahn, B. Choi, S. H. Ahn, S. H. Han, H. Lee, Synth. Met. 177, 219 (2001).

[19] I. Musa, W. Eccleston, Synth. Met.97, 69 (1998).

[20] N. Camaioni, G. Casalbore-Miceli, M. Catellani, S. Luzzzati, W. Porzio, Mat. Scienc. Eng. C 15, 261 (2001).
[21] C. Sentein, B. Mouranda, A. Rosilio, C. Rosilio, Synth. Met. 83, 27 (1996).

[22] V. N. Prigodin, A. J. Epstein, Synth. Met. 125, 43 (2002).

[23] T. Hassenkam, D. R. Greve, T. Bjфrnholm, Adv. Mater. 13, 631 (2001).

[24] A. K. Bakhshi, J. Molec. Struct. 209, 193 (1990).

[25] T. Kaniowski, S. Niziol, J. Sanetra, M. Trznadel, A. Pron, Synth. Met. 94, 111 (1998).

[26] K. Kaneto, Thin Solid Films 393, 249 (2001).

[27] L. S. Roman, O. Inganäs, Synth. Met. 125, 419 (2002).

[28] Y. Kunugi, Y. Harina, K. Yamashita, N. Ohta and S. Ito, J. Mater. Chem. 10, 2673 (2000).

[29] I. H. Campbell, P. S. Davids, J. P. Ferraris, T. W. Hagler, C. M. Heller, A. Saxena, D. L. Smith, Synth. Met. 80, 105 (1996).

[30] X. Wei, S. A. Jeglinski, Z. V. Vardeny, Synth. Met. 85, 1215 (1997).

[31] F. J. Esselink, G. Hadziioannou, Synth. Met. 75, 209 (1995).

[32] K. V. Sarathy, K. S. Narayan, J. Kim, J. O. White, Chem. Phys. Lett.318, 543 (2000).

[33] Y. Fang, S. A. Chen, Synth. Met. 52, 261 (1992).

[34] F. Garten, J. Vrijmoeth, A. R. Schlatmann, R. E. Gill, T. M. Klapwijk, G. Hadziioannou, Synth. Met.76, 85 (1996).

[35] I. Musa, W. Eccleston, Thin Solid Films 343, 469 (1999).

[36] D. Ma, I. A. Hümmelgen, R. W. C. Li, J. Gruber, J. Phys D: Appl. Phys. 33, 1376 (2000).

[37] M. Koehler, M. G. E. da Luz, I. A. Hümmelgen, J. Phys. D: Appl. Phys. 34, 1947 (2001).

[38] R. Valaski, S. Ayoub, L. Micaroni, I. A. Hümmelgen, Thin Solid Films 415, 206 (2002). 